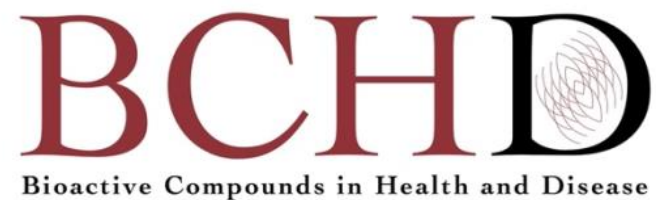

\title{
Effects of quercetin and low-level laser on oxidative and inflammatory factors among patients with type 2 diabetes mellitus and mild cognitive impairment
}

\author{
Danik Martirosyan ${ }^{1}$, Mohammad Reza Ashoori², Alireza Rezaeinezhad ${ }^{3}$, Fahimeh Jahanbakhshi ${ }^{3}$, \\ Shaghayegh Pezeshki ${ }^{4}$, Afsaneh Seyed Mikaeili ${ }^{5}$, Saham Alkhamis ${ }^{3}$, and Hossein Mirmiranpour ${ }^{*}$
}

${ }^{1}$ Functional Food Center, Functional Food Institute, Dallas, TX, USA; ${ }^{2}$ Department of Laboratory Sciences, School of Allied Medical Sciences, Zanjan University of Medical Sciences, Zanjan, Iran; ${ }^{3}$ Laser and Plasma Research Institute, Shahid Beheshti University, G. C., Tehran, Iran; ${ }^{4}$ Department of Immunology, School of Medicine, Iran University of Medical Sciences, Tehran, Iran; ${ }^{5}$ Department of Molecular and Cellular Sciences, Faculty of Advanced Sciences and Technology, Islamic Azad University, Pharmaceutical Sciences Branch, Tehran, Iran; ${ }^{6}$ Endocrinology and Metabolism Research Center (EMRC), Valiasr Hospital, School of Medicine, Tehran University of Medical Science, Tehran, Iran

*Corresponding Author: Hossein Mirmiranpour, MD, PhD, Endocrinology and Metabolism Research Center (EMRC), Valiasr Hospital, School of Medicine, Tehran University of Medical Science, Tehran, Iran.

Submission Date: December 13 ${ }^{\text {th }}, 2021$; Acceptance Date: January ${ }^{\text {th }}, 2022$; Publication Date: January $11^{\text {th }}, 2022$

Please cite this article as: Martirosyan D.M., Ashoori M.R., Rezaeinezhad A., Jahanbakhshi F., Pezeshki S., Mikaeili A.S., Alkhamis S., Mirmiranpour H. Effects of quercetin and low-level laser on oxidative and inflammatory factors among patients with type 2 diabetes mellitus and mild cognitive impairment. Bioactive Compounds in Health and Disease 2022; 5(1): 1-12. DOI: https://www.doi.org/10.31989/bchd.v5i1.877

\section{ABSTRACT}

Background: Unmanaged type 2 diabetes mellitus has dangerous consequences, such as neuropathy. Oxidative stress and inflammatory factors play an important role in the development of diabetic neuropathy. Diabetics are prone to mild cognitive impairment, which is a neurological disease. The aim of this study was to investigate the effects of quercetin as a functional food and oxidative agents and inflammatory factors of low-level laser.

Methods: In this study, 60 elderly volunteers were selected: 30 normal as a control group and 30 with type 2 diabetes mellitus and mild cognitive impairment. The average age was 75 years old. Groups of diabetic patients were examined for changes in glucose levels, oxidants, antioxidants and inflammatory factors before and after treatment with quercetin and low-level laser therapy-green laser diode with a wavelength of $532 \mathrm{~nm}$ at $100 \mathrm{mw}$ and compared with the control group. Changes in the levels of biochemical parameters were performed according to the instructions of the relevant kits. 
Results: The results of the obtained data analysis showed that there was a significant difference $(P$ value $<0.05)$ in the levels of glucose, hydrogen peroxide, advanced glycation end-products, malondialdehyde, oxidized-low density lipoprotein, paraoxonase, lipoprotein lipase, and inflammatory factors including TNF- $\alpha$, interleukin-1 alpha and interleukin-1 beta between diabetic samples before and after treatment with quercetin and laser from control subject samples. There was no significant difference ( $P$ value $>0.05$ ) in inflammatory factors between quercetin-treated, lasertreated and both quercetin and laser treated groups. The synergistic effect of quercetin and laser between the quercetin and laser treated group and the untreated group on changes in the levels of biochemical parameters was observed significantly only in advanced glycation end-products, malondialdehyde, oxidized-low density lipoprotein, and paraoxonase.

Conclusion: The results showed that quercetin, laser, and their synergistic effect can play a role in reducing some oxidant factors.

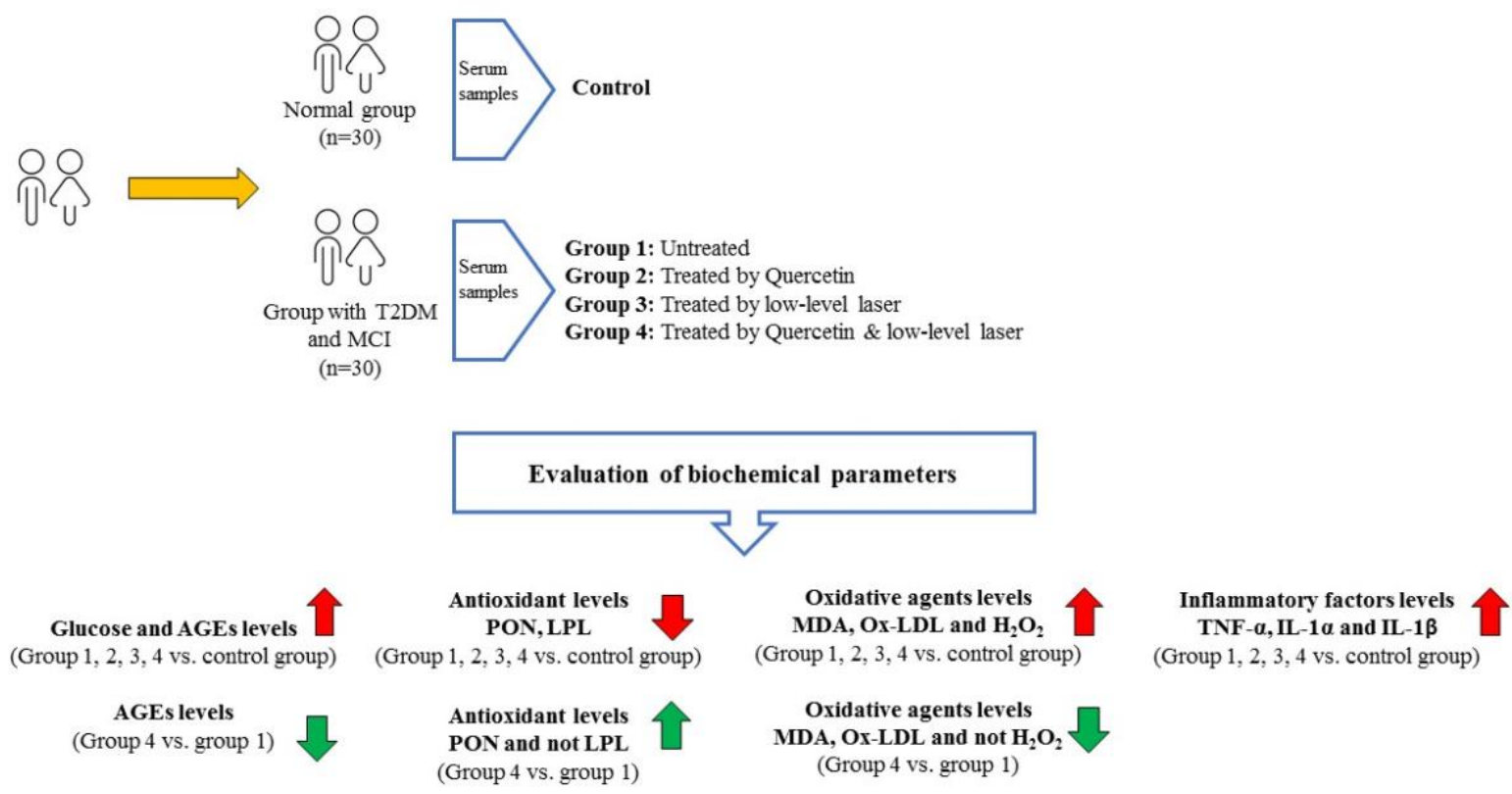

Keywords: Quercetin, Low-level laser, Inflammatory factors, Oxidative factors, Diabetes mellitus

(CFFC 2022. This is an Open Access article distributed under the terms of the Creative Commons Attribution 4.0 License (http://creativecommons.org/licenses/by/4.0)

\section{INTRODUCTION}

Diabetes mellitus (DM) is one of the most important chronic metabolic disorders that is increasing rapidly in human societies in recent decades [1]. Today, this disease related to carbohydrate metabolism is divided into two main groups: type 1 diabetes mellitus (T1DM) and type 2 diabetes mellitus (T2DM). T1DM is a complex autoimmune disease caused by the rapid and permanent degradation of insulin of beta cells in the pancreas [2-3]. T2DM is characterized by a relative lack of insulin caused by dysfunction of beta cells in the pancreas and insulin resistance in target organs [4]. The prevalence of T2DM 
is much higher than T1DM and it is projected to increase to 700 million by 2045 [5]. Problems such as neuropathy can occur if DM is not controlled and managed. One of the neurological consequences of uncontrolled DM, especially in the elderly, is mild cognitive impairment $(\mathrm{MCl})$ that may lead to Alzheimer's disease [6]. It has been shown that oxidative stress, reactive oxygen species [7], and various inflammatory cytokines are involved in the pathogenesis of type 1 and type 2 diabetes and its consequences, such as neuropathy, due to uncontrolled diabetes $[8,9]$. Tumor necrosis factor- $\alpha$ (TNF- $\alpha)$ is one of the most important pro-inflammatory mediators that is involved in insulin resistance and T2DM pathogenesis [10]. In uncontrolled DM, the formation of advanced glycation end products (AGEs) and oxidative stress are interrelated. Increased AGEs may lead to oxidative stress and vice versa; ROS may facilitate the formation of AGEs [11]. Another destructive effect of ROS is the activation of stable aldehydes, such as malondialdehyde (MDA) active aldehydes, which damage cell membranes [12-13]. MDA is a biomarker of lipid damage mediated by free radicals and oxidative stress [14].

Antioxidants can reduce or inhibit molecular oxidation. Proper diet as a source of antioxidants is especially important in maintaining good health. Today, experimental studies have shown that plants with antioxidant activity are effective in treating and preventing the complications of diabetes [15]. One of these antioxidants is quercetin (Figure 1). Quercetin is an important flavonol among flavonoids. Its name has been used since 1857 [16]. Quercetin is found in fruits, vegetables, nuts, seeds and wines [17]. In general, flavonoid antioxidants such as quercetin reduce the damaging effects of free radicals. In this way, they are involved in the prevention and control of diseases such as DM, high blood pressure and neurological diseases [17].
Studies have reported that quercetin may play a role in controlling and improving DM and its consequences [1820] by reducing oxidative stress, as evidenced by lower MDA levels [21].<smiles>O=c1c(O)c(-c2ccc(O)c(O)c2)oc2cc(O)cc(O)c12</smiles>

Figure 1. Chemical structure of quercetin

Today, low-level laser therapy (LLLT) is being widely used in medical studies. This treatment can reduce the inflammatory process by acting on inflammatory markers, tumor necrosis factor alpha (TNF- $\alpha$ ) and interleukin-1 beta (IL-1 $\beta$ ) [22]. The role of antioxidant enzymes in counteracting oxidative damage in DM is very important. Paraoxonase (PON) is an important plasma antioxidant enzyme that protects lipoproteins from oxidative damage. Low levels of serum paraoxonase are associated with an increased risk of cardiovascular consequences of T2DM [23-24]. Lipoprotein lipase (LPL) is involved in lipid metabolism. Decreased activity of this enzyme is associated with DM [25]. Studies have also reported that LLLT can reduce oxidative stress by modulating ROS [26] and increasing the activity of antioxidant enzymes such as PON [27]. In this study, we aimed to investigate the synergistic effects of quercetin and LLLT on oxidative stress and inflammatory factors in patients with T2DM and $\mathrm{MCl}$.

\section{MATERIALS AND METHODS}

Materials: Quercetin was purchased from sigma (PHR 1488). The enzyme-linked immunosorbent assay (ELISA) kit to assay human glucose levels (with an intra- and inter-assay $\mathrm{CV}<8 \%$ and $<10 \%$, respectively) was purchased from MyBioSource Inc. (San Diego, USA). The hydrogen peroxide $\left(\mathrm{H}_{2} \mathrm{O}_{2}\right)$ assay kit was purchased from ZellBio (ZellBio GmbH, Ulm, Germany) for the measurement of $\mathrm{H}_{2} \mathrm{O}_{2}$ levels. The colorimetric method 
was used to study changes in paraoxonase (PON), lipoprotein lipase (LPL), and MDA levels. The MDA assay kit was procured from Cayman chemical company (Cayman Chemical, 1180 East Ellsworth Road, Ann Arbor, Michigan 48108 USA).

Additionally, AGEs parameters were evaluated by the method of Kalousova et al [28]. The concentration of oxidized-low density lipoprotein (Ox-LDL) was determined by the kit purchased from Mercodia Company (Uppsala. Sweden). Ox-LDL levels were measured by ELISA method. In the current study, the concentration of inflammatory factors, such as interleukin-1 alpha (IL-1 $\alpha$ ), IL-1 $\beta$, and TNF- $\alpha$, was studied using the ELISA method. Test kits for IL-1 $\alpha$ and IL-1 $\beta$ were purchased from Diaclone (25020 Besancon cedex, France). The TNF- $\alpha$ analytical kit was procured from R\&D Systems, Inc. (614 McKinley Place NE Minneapolis, MN 55413).

\section{Methods}

Participants: In this study, 30 healthy people as a control group and 30 patients with T2DM and $\mathrm{MCl}$ were selected from among the persons referred to Vali-Asr medical laboratory in Tehran, Iran. Concurring to the World Health Organization (WHO) criteria, individuals with fasting plasma glucose $\geq 126 \mathrm{mg} / \mathrm{dL}$ or glycated hemoglobin $(\mathrm{HbA} 1 \mathrm{c}) \geq 6.5 \%$ were considered as diagnosed T2DM. Individuals with T2DM co-morbid with cardiovascular illness were prohibited from consideration. Informed consent was obtained from all patients.

The sample of diabetic patients was divided into four groups.

Group 1: Samples of diabetics before treatment with quercetin or laser (Diabetic).

Group 2: Samples of diabetics after treatment with quercetin (Diabetic + Quercetin).

Group 3: Samples from diabetic patients after laser treatment. The laser was irradiated on the serum samples of these people. (Diabetic + Laser).
Group 4: Diabetic patients treated with both quercetin and laser irradiation (Diabetic + Quercetin + Laser).

After determining the control and diabetic groups and dividing the samples of the diabetic groups into four groups, blood samples were taken from all control and diabetic groups. The biochemical variables depicted above were measured in control and diabetics before untreated with quercetin and laser irradiation (as group 1). The serum sample separated from diabetic subjects was irradiated with laser before using quercetin and then the mentioned biochemical parameters in their serum sample were examined (as group 3). At that point, the same patients were treated with quercetin (at a dose of $75 \mathrm{mg}$ per day) for two weeks [29]. After two weeks, a blood test was taken from them. Once more, biochemical variables were measured before laser irradiation (as group 2) and after laser irradiation (as group 4). During treatment with quercetin, the patient group received their main drugs, including memantine.

General Features and Sampling: The age, sex, weight, height, and body mass index (BMI) of all study patients were recorded. Blood samples were taken from all patients after 12 hours of nighttime fasting. After collecting the blood sample, they were centrifuged (250 $\mathrm{g}$ for $10 \mathrm{~min})$; following this, the serum was separated from the centrifuged samples. Isolated serum samples were used to assess the biochemical endpoints and antioxidant enzymes described earlier.

Laser Irradiation: The samples were irradiated with a low-level green laser pointer diode with a wavelength of $532 \mathrm{~nm}$ at $100 \mathrm{mw}$ in continuous mode with divergence < 1.5 mRad, beam mode (TEMoo), aperture beam diameter 1.5 , crystal type Nd:VYO4:KTP and power supply $1 \times 3 \mathrm{~V}$ CR2 alkaline batteries. The laser power density was $509.55 \mathrm{~mW} / \mathrm{cm}^{2}$ at a distance of $6.5 \mathrm{~cm}$ between the laser device and the serum in the tube; the diameter of the laser spot was fixed to $0.5 \mathrm{~cm}$. As in our previous study, the irradiation was applied for 8 seconds. 
Green diode pumped solid state (DPSS) Laser Pointer (model RLP-532, 1040 Vienna, Austria) was used for LLLT [30].

Statistical Analysis: Statistical analysis was done by SPSS (version 23, IBM, USA) software for Windows. All results were expressed as mean \pm standard deviation (SD). Independent-sample T-test was used to compare the mean of general characteristics of the participants. Statistical significance was analyzed by one-way ANOVA to compare the mean of the obtained data. After the oneway ANOVA test, Tukey post hoc was used. The Kolmogorov-Smirnov test was used to analyze the normal

Table 1. Anthropometric data

\begin{tabular}{|c|c|c|c|}
\hline Feature & Control Sample $(\mathbf{n = 3 0})$ & Diabetic Sample $(\mathbf{n = 3 0})$ & P value \\
\hline Height $(\mathrm{Cm})$ & $165.8 \pm 6.4$ & $167.9 \pm 6.2$ & 0.20 \\
\hline Weight $(\mathrm{Kg})$ & $85.2 \pm 5.4$ & $85.8 \pm 4.7$ & 0.69 \\
\hline BMI $\left(\mathrm{Kg} / \mathrm{m}^{2}\right)$ & $31.1 \pm 3.2$ & $30.6 \pm 2.9$ & 0.46 \\
\hline
\end{tabular}

Data are given as mean \pm SD. $p<0.05$ is significant.

Biochemical Parameters: We also evaluated some important biomedical parameters in serum samples from the control group and diabetics group. These biochemical variables included blood glucose, antioxidant enzymes (PON, and $L P L)$, an oxidizing agent $\left(\mathrm{H}_{2} \mathrm{O}_{2}\right)$, and inflammatory agents (IL-1 $\alpha, \mathrm{IL}-1 \beta$, and TNF- $\alpha$ ). Changes in the concentration of biochemical variables were investigated in the serum samples of the control group and the serum samples of subjects with type $2 \mathrm{DM}$ in groups 1, 2, 3, and 4. An assessment of the results of inflammatory factors (IL-1 $\alpha, \mathrm{IL}-1 \beta$, and TNF- $\alpha$ ) between the control group and the four diabetic groups is presented in Figure 2 and Figure 3. A comparison of the consequences of other biochemical variables such as glucose, $\mathrm{H}_{2} \mathrm{O}_{2}$, antioxidant parameters ( $\mathrm{LPL}$, and PON), and AGE, MDA, and ox-LDL. is shown in Table 2. There was a statistically significant difference $(P$ value $<0.05)$ in the results of groups 1 to 4 compared to the control distribution of data. P-values $<0.05$ were considered significant.

\section{RESULTS}

General Features: The age of contributing volunteers was between 65 and 80 years old. In control group, 50\% were male $(n=15)$ and $50 \%$ were female $(n=15)$. In the group of people with T2DM (diabetic group), 50\% were female $(n=15)$ and $50 \%$ were male $(n=15)$. The results for the general features of control and diabetic groups are given in Table 1. As shown in Table 1, the height, weight, and $\mathrm{BMI}$ of control individuals were compared with those of diabetics. There was no statistically significant difference in the comparison of general features between control and diabetic groups. 
(Figure 2 and Figure 3). A significant difference was the group treated with both quercetin and laser detected in the comparison of AGEs, MDA, and Ox-LDL in irradiation, compared to the untreated diabetic group.

Table 2. Comparison between the levels of biochemical parameters of the control group (non-diabetics) with the four groups of diabetics.

\begin{tabular}{|c|c|c|c|c|c|c|}
\hline $\begin{array}{l}\text { Groups } \\
\text { Biochemical } \\
\text { parameters }\end{array}$ & Control & Group 1 & Group 2 & Group 3 & Group 4 & $P$ value \\
\hline PON (U/ml) & $180.2 \pm 6.9$ & $103.2 \pm 4.9$ & $106.4 \pm 7.9$ & $107.8 \pm 5.4$ & $108.2 \pm 4.9$ & $<0.001$ \\
\hline $\mathrm{LPL}(\mathrm{pg} / \mathrm{ml})$ & $1386.5 \pm 45.9$ & $867.5 \pm 45.9$ & $869.5 \pm 45.9$ & $871.9 \pm 41.1$ & $872.9 \pm 43.6$ & $<0.001$ \\
\hline $\mathrm{Glc}(\mu \mathrm{g} / \mathrm{ml})$ & $219.5 \pm 20.2$ & $387.9 \pm 22.5$ & $385.4 \pm 19.8$ & $384.4 \pm 19.9$ & $382.9 \pm 22.5$ & $<0.001$ \\
\hline $\mathrm{H}_{2} \mathrm{O}_{2}(\mu \mathrm{M} / \mathrm{ml})$ & $242.6 \pm 18.6$ & $350.3 \pm 25.5$ & $340.3 \pm 25.5$ & $337.9 \pm 15.1$ & $335.3 \pm 25.5$ & $<0.001$ \\
\hline AGEs (AU) & $39.1 \pm 5.1$ & $83.1 \pm 5.9$ & $73.0 \pm 5.9$ & $72.4 \pm 6.7$ & $70.6 \pm 5.9$ & $<0.001$ \\
\hline $\mathrm{MDA}(\mu \mathrm{M} / \mathrm{ml})$ & $2.2 \pm 0.1$ & $3.0 \pm 0.2$ & $2.9 \pm 0.2$ & $2.8 \pm 0.2$ & $2.8 \pm 0.2$ & $<0.001$ \\
\hline Ox-LDL (mU/I) & $10.6 \pm 0.8$ & $18.5 \pm 1.2$ & $14.3 \pm 0.8$ & $13.9 \pm 0.6$ & $12.8 \pm 0.9$ & $<0.001$ \\
\hline
\end{tabular}

Data are given as mean \pm SD. Control: non-diabetic, not treated. Group 1: Diabetic Untreated. Group 2: Diabetic + Quercetin. Group 3: Diabetic + Laser. Group 4: Diabetic + Quercetin + Laser. PON, paraoxonase; LPL, lipoprotein lipase; IL-1 $\alpha$, Interleukin 1 alpha; IL-1 $\beta$, Interleukin 1 beta; and TNF- $\alpha$, tumor necrosis factor alpha; Glc, glucose; AGEs, advanced glycation end products; MDA, malondialdehyde; Ox-LDL, oxidized low-density lipoprotein.

Table 3. Multiple comparisons between the levels of biochemical parameters between the diabetic groups

\begin{tabular}{|c|c|c|c|c|c|c|c|c|}
\hline $\begin{array}{l}\text { Biochemical } \\
\text { parameters }\end{array}$ & & $\begin{array}{l}\text { PON } \\
\text { (U/ml) }\end{array}$ & $\mathrm{LPL}(\mathrm{pg} / \mathrm{ml})$ & $\mathrm{Glc}(\mu \mathrm{g} / \mathrm{ml})$ & $\begin{array}{l}\mathrm{H}_{2} \mathrm{O}_{2} \\
(\mu \mathrm{M} / \mathrm{ml})\end{array}$ & AGEs (AU) & $\begin{array}{l}\text { MDA } \\
(\mu \mathrm{M} / \mathrm{ml})\end{array}$ & $O x-L D L(m U / l)$ \\
\hline Group 1 & $\begin{array}{l}\text { Group } 2 \\
\text { Group } 3 \\
\text { Group } 4\end{array}$ & $\begin{array}{l}0.06 \\
<0.0001 \\
0.001\end{array}$ & $\begin{array}{l}0.86 \\
0.71 \\
0.66\end{array}$ & $\begin{array}{l}0.65 \\
0.58 \\
0.38\end{array}$ & $\begin{array}{l}0.17 \\
0.02 \\
0.03\end{array}$ & $\begin{array}{l}<0.0001 \\
<0.0001 \\
<0.0001\end{array}$ & $\begin{array}{l}0.002 \\
<0.0001 \\
<0.0001\end{array}$ & $\begin{array}{l}<0.0001 \\
<0.0001 \\
<0.0001\end{array}$ \\
\hline Group 2 & $\begin{array}{l}\text { Group } 1 \\
\text { Group } 3 \\
\text { Group } 4\end{array}$ & $\begin{array}{l}0.06 \\
0.40 \\
0.33\end{array}$ & $\begin{array}{l}0.86 \\
0.85 \\
0.76\end{array}$ & $\begin{array}{l}0.65 \\
0.84 \\
0.63\end{array}$ & $\begin{array}{l}0.17 \\
0.64 \\
0.39\end{array}$ & $\begin{array}{l}<0.0001 \\
0.68 \\
0.09\end{array}$ & $\begin{array}{l}0.002 \\
0.75 \\
0.35\end{array}$ & $\begin{array}{l}<0.0001 \\
0.07 \\
<0.0001\end{array}$ \\
\hline Group 3 & $\begin{array}{l}\text { Group } 1 \\
\text { Group } 2 \\
\text { Group } 4\end{array}$ & $\begin{array}{l}<0.0001 \\
0.40 \\
0.74\end{array}$ & $\begin{array}{l}0.71 \\
0.85 \\
0.92\end{array}$ & $\begin{array}{l}0.58 \\
0.84 \\
0.80\end{array}$ & $\begin{array}{l}0.02 \\
0.64 \\
0.65\end{array}$ & $\begin{array}{l}<0.0001 \\
0.68 \\
0.33\end{array}$ & $\begin{array}{l}<0.0001 \\
0.75 \\
0.55\end{array}$ & $\begin{array}{l}<0.0001 \\
0.07 \\
<0.0001\end{array}$ \\
\hline Group 4 & $\begin{array}{l}\text { Group } 1 \\
\text { Group } 2 \\
\text { Group } 3\end{array}$ & $\begin{array}{l}0.001 \\
0.33 \\
0.74\end{array}$ & $\begin{array}{l}0.66 \\
0.76 \\
0.92 \\
\end{array}$ & $\begin{array}{l}0.38 \\
0.63 \\
0.80\end{array}$ & $\begin{array}{l}0.03 \\
0.39 \\
0.65\end{array}$ & $\begin{array}{l}<0.0001 \\
0.09 \\
0.33\end{array}$ & $\begin{array}{l}<0.0001 \\
0.35 \\
0.55\end{array}$ & $\begin{array}{l}<0.0001 \\
<0.0001 \\
<0.0001\end{array}$ \\
\hline & & & & & $P$ value & & & \\
\hline
\end{tabular}

$P$ value $<0.05$ is significant. Group1: Diabetic Untreated. Group 2: Diabetic + Quercetin. Group 3: Diabetic + Laser. Group 4: Diabetic + Quercetin + Laser. PON, paraoxonase; LPL, lipoprotein lipase; Glc, glucose; AGEs, advanced glycation end products; MDA, malondialdehyde; Ox-LDL, oxidized low-density lipoprotein. 


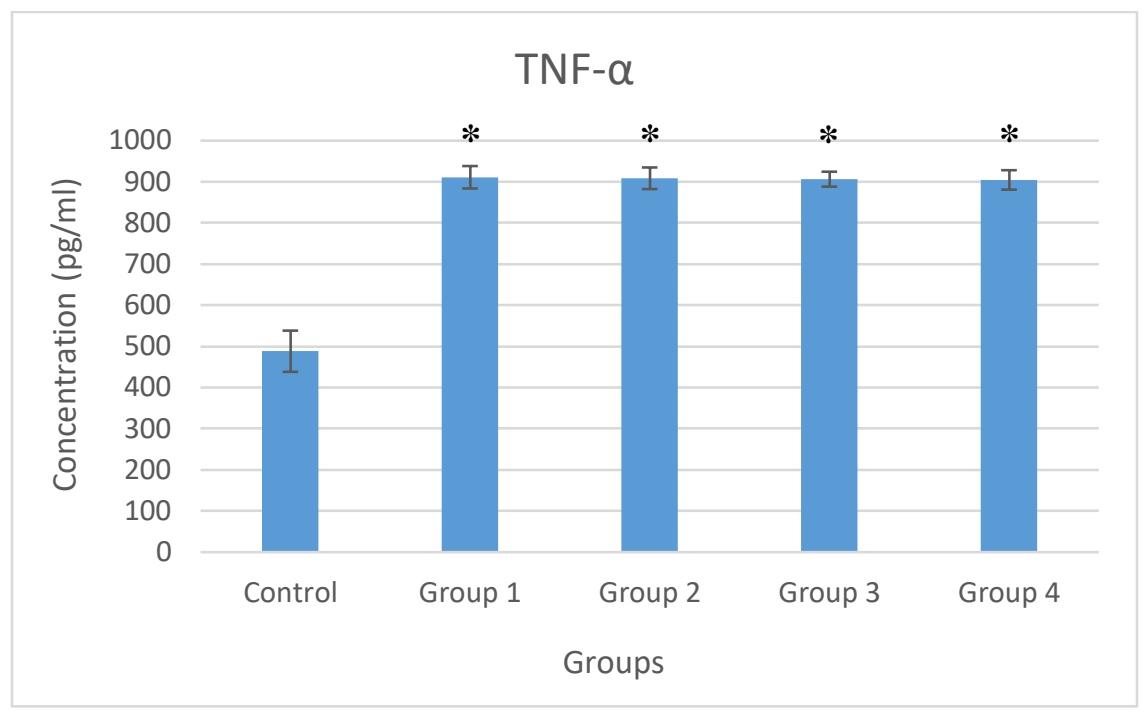

Figure 2. Changes in TNF- $\alpha$ levels in the control group and diabetic samples in different conditions. ${ }^{*} p<0.05$ vs. Control. Group 1: Diabetic Untreated. Group 2: Diabetic + Quercetin. Group 3: Diabetic + Laser. Group 4: Diabetic + Quercetin + Laser.

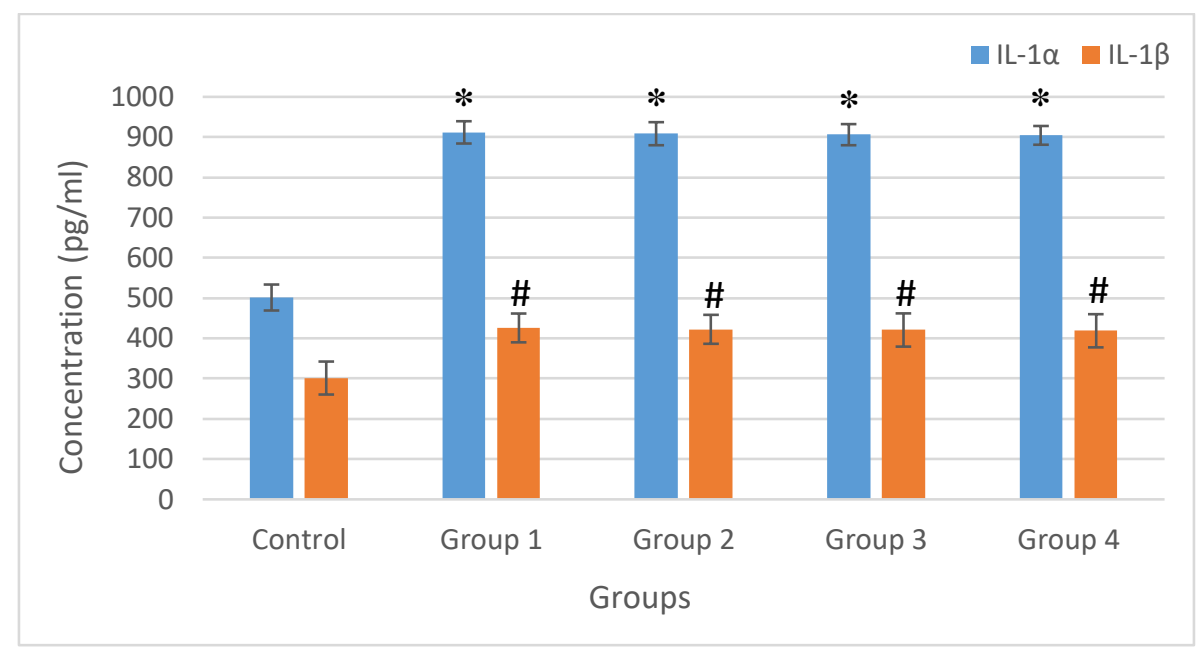

Figure 3. Changes in IL-1 $\alpha$ and IL-1 $\beta$ levels in the control and diabetic groups (in different conditions). * and \# $p<0.05$ vs. Control. Group 1: Diabetic Untreated. Group 2: Diabetic + Quercetin. Group 3: Diabetic + Laser. Group 4: Diabetic + Quercetin + Laser.

\section{DISCUSSION}

In this study, we evaluated the effect of functional food and physical method on diabetes. For this purpose, we used quercetin and a low-level laser on samples of diabetics. According to the results of Table 2 and Figures 2 and 3, a significant difference was observed between the measured parameters between the diabetic group and the control group. This significant difference was also observed in the treated diabetic groups compared to the control group. The results showed that treatment of the samples with quercetin or laser irradiation can decrease oxidative stress and inflammation parameters. Also, the obtained data revealed that the use of quercetin or laser irradiation leads to a synergistic effect.

There are several studies which show laser irradiation can modify protein structures and change their activities. Simoes et al. evaluated protein concentration and enzymatic activities by irradiating parotid and submandibular glands using an infrared diode laser [31]. They reported that peroxidase and catalase activities of rat submandibular and parotid glands irradiated with $4 \mathrm{~J} / \mathrm{cm}^{2}$ and $8 \mathrm{~J} / \mathrm{cm}^{2}$ was increased. However, the activity of lactate dehydrogenase (LDH) and amylase were decreased. In another study, Silva and 
Potrich irradiated amylase with GaAlAs laser at different doses. They stated that enzymes have an optimal laser range (dose) at which their activity is maximized, while with increase or decrease of laser dose, activity decreases. Also, they expressed the effect of $\mathrm{pH}$ and temperature induced by laser irradiation must be considered for the proper choosing of the optimum dosage on modulation of enzymatic activity [32]. Overall, the increase of PON and LPL activities may be due to modification of their structure with laser irradiation.

Moreover, the use of laser irradiation on diabetic samples resulted in a decrease in $\mathrm{H}_{2} \mathrm{O}_{2}$ content and oxidation by-products including MDA and ox-LDL. Based on our previous studies, the laser treatment could modify glycated protein enzymes (such as superoxide dismutase, catalase and glutathione peroxidase), recover their enzymatic activity, and thereby, improve the antioxidant defense system [33]. Also, there are different studies that confirm the decrease of oxidative stress through the improvement of antioxidant activities by irradiation of different type-lasers [34-35]. Another possible mechanism can be the photo modulation of mitochondrial activity and ROS production [36]. Amaroli et al. evaluated the interaction of a $980 \mathrm{~nm}$ diode laser light and mitochondrial activity. They reported an inhibitory effect at low power, no effect at intermediate power, an increase of ATP production at high power, and recovery of the ATP synthesis to the control level at higher power [37].

Based on the results, the inflammatory parameters decrease after laser therapy. Rezaeinezhad et al. in several studies demonstrated that inflammation can be reduced following a decrease in oxidative stress [38-39].

Quercetin, as a plant ingredient, is possibly the flavonoid with the strongest antioxidant and antiinflammatory activities [20, 40-44]. So, the decrease of oxidative stress and inflammation as the results of using quercetin is a logical result. In this study, we evaluated the effect of laser and quercetin on diabetics' samples.
The results showed that they can have synergistic effects such that inflammation and oxidative stress in the group which received both laser and quercetin therapies are more decreased than other groups which receive laser and quercetin separately. Ahmed et al. studied the effect of quercetin and low-level laser therapy on wound healing in diabetic rats [45]. They found that the use of laser and quercetin therapy led to a larger production of insulin and a larger decrease in the secretion of proinflammatory cytokines than in rats that received only laser irradiation or only quercetin treatment. These observations are in line with our results. In a study by Bhuiyan et al., [46] the effect of quercetin on AGEs formation was studied. They reported that quercetin could play a role in reducing the formation of AGEs as well as ROS by chelating metal ions. In this case, our results agree with the study of Bhuiyan et al. Studies have shown that quercetin can inhibit the formation of ox-LDL through a variety of pathways as well as by regulating the expression of various genes [47-48]. In our study, a significant decrease in ox-LDL levels was observed in the treated groups with quercetin and LLL, but the effect of quercetin in reducing the levels of inflammatory factors was not significant. Zhao et al. [49] showed that quercetin significantly reduced the expression of TNF- $\alpha$ and IL-1ß. They also stated that quercetin do not decrease blood glucose levels in a diabetic rat model.

\section{CONCLUSION}

According to our results, laser therapy is effective to decrease oxidative stress induced by diabetes. Also, quercetin as an antioxidant and anti-inflammatory agent likely had a significant role in decreasing biomarkers of oxidative stress. Moreover, the results showed that the use of laser and quercetin simultaneously could have synergistic effects. 
List of Abbreviations: DM: diabetes mellitus, T1DM: type 1 diabetes mellitus, T2DM, type 2 diabetes mellitus, $\mathrm{MCl}$ : mild cognitive impairment, AGEs: advanced glycation end-products, MDA: malondialdehyde, LLLT: low-level laser therapy, ELISA: enzyme-linked immunosorbent assay, $\mathrm{H}_{2} \mathrm{O}_{2}$ : hydrogen peroxide, Ox-LDL: oxidized-low density lipoprotein, IL-1 $\alpha$ : interleukin-1 alpha, IL-1 $\beta$ : interleukin-1 beta, TNF- $\alpha$ : tumor necrosis factor alpha, PON: paraoxonase, LPL: lipoprotein lipase, WHO: world health organization, $\mathrm{HbA} 1 \mathrm{c}$ : glycated hemoglobin, BMI: body mass index, DPSS: diode pumped solid state, LDH: lactate dehydrogenase, ATP: adenosine triphosphate.

Author's contributions: DM was involved in the planning of the study and the article final editing. MRA participated in the writing. SA and AR assisted in lowlevel laser therapy and doing experimental work. FJ and SP contributed to data collection and analysis of the results. ASM participated in the abstract writing. HM recruited the patients and supervised the project. All authors read and approved the final version before its submission.

Conflict of interest: The authors declare that there is no conflict of interest.

Acknowledgments: The authors of this manuscript would like to thank the staff of Vali-Asr medical laboratory.

\section{REFERENCES}

1. Asgharzadeh, F., A. Tanomand, M.R. Ashoori, A. Asgharzadeh, and N. Zarghami: Investigating the effects of Lactobacillus casei on some biochemical parameters in diabetic mice. J Endocrinol Metabol Diabetes S AF 2017, 22(3): 47-50.

https://doi.org/10.1080/16089677.2017.1378460

2. Norris, J.M., R.K. Johnson, and L.C. Stene: Type 1 diabetesearly life origins and changing epidemiology. Lancet Diabetes Endocrinol 2020, 8(3): 226-238.

https://doi.org/10.1016/S2213-8587(19)30412-7
3. Craig, M., S. Twigg, K.a. Donaghue, N. Cheung, F. Cameron, J. Conn, A. Jenkins, and M. Silink: National evidence-based clinical care guidelines for type 1 diabetes in children, adolescents and adults. Canberra: Australian Government Department of Health and Ageing 2011, 346

4. Zhou, B., Y. Lu, K. Hajifathalian, J. Bentham, M. Di Cesare, G. Danaei, H. Bixby, M.J. Cowan, M.K. Ali, and C. Taddei: Worldwide trends in diabetes since 1980: a pooled analysis of 751 population-based studies with 4.4 million participants. The Lancet 2016, 387(10027): 1513-1530.

https://doi.org/10.1016/S0140-6736(16)00618-8

5. Saeedi, P., I. Petersohn, P. Salpea, B. Malanda, S. Karuranga, N. Unwin, S. Colagiuri, L. Guariguata, A.A. Motala, and K. Ogurtsova: Global and regional diabetes prevalence estimates for 2019 and projections for 2030 and 2045: Results from the International Diabetes Federation Diabetes Atlas. Diabetes Res Clin Pract 2019, 157: 107843.

https://doi.org/10.1016/j.diabres.2019.107843

6. Alimoradzadeh, R., H. Mirmiranpour, P. Hashemi, S. Pezeshki, and S.S. Salehi: Effect of Memantine on Oxidative and Antioxidant Indexes Among Elderly Patients with Prediabetes and Mild Cognitive Impairment. J Neurol Neurophysiol 2019, 10(1): 1-5.

7. Martirosyan, D., M.R. Ashoori, and H. Mirmiranpour: The effect of low level-laser irradiation on antioxidant enzymes and mineral levels in serum of patients with type 2 diabetes mellitus. Bioact Compd Health Dis 2020, 3(5): 82-89.

https://doi.org/10.4172/2155-9562.1000483

8. Darenskaya, M., L. Kolesnikova, and S. Kolesnikov: Oxidative stress: Pathogenetic role in diabetes mellitus and its complications and therapeutic approaches to correction. Bull Exp Biol Med 2021, 171(2): 179-189. https://doi.org/10.1007/s10517-021-05191-7

9. Martirosyan, D., M. Shahnazari-Aval, M.R. Ashoori, A.S. Mikaeili, M. Nakhjavani, and H. Mirmiranpour: The effect of electron beam on oxidative stress and inflammatory factors in diabetes mellitus: An in vitro and in vivo study. Func Foods Health dis 2021, 11(7): 333-334. https://doi.org/10.31989/ffhd.v11i7.803

10. Akash, M.S.H., K. Rehman, and A. Liaqat: Tumor necrosis factor-alpha: role in development of insulin resistance and pathogenesis of type 2 diabetes mellitus. J Cell Biochem 2018, 119(1): 105-110. 
https://doi.org/10.1002/icb.26174

11. Koska, J., A. Saremi, S. Howell, G. Bahn, B. De Courten, H. Ginsberg, P.J. Beisswenger, and P.D. Reaven: Advanced glycation end products, oxidation products, and incident cardiovascular events in patients with type 2 diabetes. Diabetes Care 2018, 41(3): 570-576. https://doi.org/10.2337/dc17-1740

12. Ayala, A., M.F. Muñoz, and S. Argüelles: Lipid peroxidation: production, metabolism, and signaling mechanisms of malondialdehyde and 4-hydroxy-2-nonenal. Oxid Med Cell Longev 2014, 2014: 1-32. https://doi.org/10.1155/2014/360438

13. Phaniendra, A., D.B. Jestadi, and L. Periyasamy: Free radicals: properties, sources, targets, and their implication in various diseases. Indian J Clin Biochem 2015, 30(1): 11-26. https://doi.org/10.1007/s12291-014-0446-0

14. Tiwari, B.K., K.B. Pandey, A. Abidi, and S.I. Rizvi: Markers of oxidative stress during diabetes mellitus. J Biomark 2013, 2013: 1-9. http://dx.doi.org/10.1155/2013/378790

15. Rajendiran, D., S. Packirisamy, and K. Gunasekaran: A review on role of antioxidants in diabetes. Asian J Pharm Clin Res 2018, 11(2): 48-53.

\section{http://dx.doi.org/10.22159/ajpcr.2018.v11i2.23241}

16. Kim, J.K. and S.U. Park: Quercetin and its role in biological functions: an updated review. EXCLI J 2018, 17: 856-863. http://dx.doi.org/10.17179/excli2018-1538

17. Oboh, G., A.O. Ademosun, and O.B. Ogunsuyi: Quercetin and its role in chronic diseases. Nat Rev Drug Discov 2016, 377 387. https://doi.org/10.1007/978-3-319-41342-6_17

18. Choi, H.-N., S.-M. Jeong, G.H. Huh, and J.-I. Kim: Quercetin ameliorates insulin sensitivity and liver steatosis partly by increasing adiponectin expression in ob/ob mice. Food Sci Biotechnol 2015, 24(1): 273-279.

\section{https://doi.org/10.1007/s10068-015-0036-9}

19. Henagan, T., W. Cefalu, D. Ribnicky, R. Noland, K. Dunville, W. Campbell, L. Stewart, L. Forney, T. Gettys, and J. Chang: In vivo effects of dietary quercetin and quercetin-rich red onion extract on skeletal muscle mitochondria, metabolism, and insulin sensitivity. Genes Nutr 2015, 10(1): 2.

https://doi.org/10.1007/s12263-014-0451-1

20. Shi, G.-J., Y. Li, Q.-H. Cao, H.-X. Wu, X.-Y. Tang, X.-H. Gao, J.Q. Yu, Z. Chen, and Y. Yang: In vitro and in vivo evidence that quercetin protects against diabetes and its complications: $\mathrm{A}$ systematic review of the literature. Biomed Pharmacother 2019, 109: 1085-1099.

https://doi.org/10.1016/j.biopha.2018.10.130

21. Singh, S., V. Kushwah, A.K. Agrawal, and S. Jain: Insulin-and quercetin-loaded liquid crystalline nanoparticles: implications on oral bioavailability, antidiabetic and antioxidant efficacy. Nanomedicine 2018, 13(5): 521-537. https://doi.org/10.2217/nnm-2017-0278

22. Aimbire, F., R. Albertini, M. Pacheco, H. Castro-Faria-Neto, P. Leonardo, V. Iversen, R. Lopes-Martins, and J. Bjordal: Lowlevel laser therapy induces dose-dependent reduction of TNF $\alpha$ levels in acute inflammation. Photomed Laser Surg 2006, 24(1): 33-37. https://doi.org/10.1089/pho.2006.24.33

23. Patra, S.K., K. Singh, and R. Singh: Paraoxonase 1: a better atherosclerotic risk predictor than HDL in type 2 diabetes mellitus. Diabetes Metab Syndr 2013, 7(2): 108-111.

https://doi.org/10.1016/j.dsx.2013.02.007

24. Shaik, A.H., N.R. Shaik, A.K. Mohammed, S.Y. Al Omar, A. Mohammad, T.A. Mohaya, and L.D. Kodidhela: Terminalia pallida fruit ethanolic extract ameliorates lipids, lipoproteins, lipid metabolism marker enzymes and paraoxonase in isoproterenol-induced myocardial infarcted rats. Saudi J Biol Sci 2018, 25(3): 431-436. https://doi.org/10.1016/j.sjbs.2017.11.002

25. Beijer, K., C. Nowak, J. Sundström, J. Ärnlöv, T. Fall, and L. Lind: In search of causal pathways in diabetes: a study using proteomics and genotyping data from a cross-sectional study. Diabetologia 2019, 62(11): 1998-2006.

https://doi.org/10.1007/s00125-019-4960-8

26. Luo, L., Z. Sun, L. Zhang, X. Li, Y. Dong, and T.C.-Y. Liu: Effects of low-level laser therapy on ROS homeostasis and expression of IGF-1 and TGF- $\beta 1$ in skeletal muscle during the repair process. Lasers Med Sci 2013, 28(3): 725-734.

https://doi.org/10.1007/s10103-012-1133-0

27. Martirosyan, D., H. Ghomi, M.R. Ashoori, A. Rezaeinezhad, A.S. Mikaeili, F. Jahanbakhshi, and H. Mirmiranpour: Study of the effect of gallic acid and cold plasma on the levels of inflammatory factors and antioxidants in the serum sample of subjects with type 2 diabetes mellitus. Bioact Compd Health Dis 2021, 4(8): 167-179.

https://doi.org/10.31989/bchd.v4i8.824 
28. Kalousova, M., J. Skrha, and T. Zima: Advanced glycation end-products and advanced oxidation protein products in patients with diabetes mellitus. Physiol Res 2002, 51(6): 597604. https://doi.org/10.1159/000066956

29. Egert, S., S. Wolffram, A. Bosy-Westphal, C. BoeschSaadatmandi, A.E. Wagner, J. Frank, G. Rimbach, and M.J. Mueller: Daily quercetin supplementation dosedependently increases plasma quercetin concentrations in healthy humans. J Nutr 2008, 138(9): 1615-1621.

https://doi.org/10.1093/jn/138.9.1615

30. Zahra Al Timimi, M. and M.Z.M. Jafri: Photodynamic therapy and green laser blood therapy. Glob J Med Res 2011, 11(5): 1-7.

31. Simões, A., W.L. Siqueira, M.L. Lamers, M.F. Santos, C. de Paula Eduardo, and J. Nicolau: Laser phototherapy effect on protein metabolism parameters of rat salivary glands. Lasers Med Sci 2009, 24(2): 202-208. https://doi.org/10.1007/s10103-008-0548-0

32. Da Silva, N.S. and J.W. Potrich: Effect of GaAlAs laser irradiation on enzyme activity. Photomed Laser Surg 2010, 28(3): 431-434. https://doi.org/10.1089/pho.2008.2410

33. Mirmiranpour, H., F.S. Nosrati, S.O. Sobhai, S.N. Takantape, and A. Amjadi: Effect of low-level laser irradiation on the function of glycated catalase. J Lasers Med Sci 2018, 9(3): 212. https://doi.org/ 10.15171/jlms.2018.38

34. Silva Macedo, R., M. Peres Leal, T.T. Braga, É.D. Barioni, S. de Oliveira Duro, A.C. Ratto Tempestini Horliana, N.O.S. Câmara, T. Marcourakis, S.H.P. Farsky, and A. Lino-dosSantos-Franco: Photobiomodulation therapy decreases oxidative stress in the lung tissue after formaldehyde exposure: role of oxidant/antioxidant enzymes. Mediat Inflamm 2016, 2016: 1-10.

https://doi.org/10.1155/2016/9303126

35. Silveira, P.C.L., L.A. Silva, T.P. Freitas, A. Latini, and R.A. Pinho: Effects of low-power laser irradiation (LPLI) at different wavelengths and doses on oxidative stress and fibrogenesis parameters in an animal model of wound healing. Lasers Med Sci 2011, 26(1): 125-131.

\section{https://doi.org/10.1007/s10103-010-0839-0}

36. Huang, Y.Y., K. Nagata, C.E. Tedford, T. McCarthy, and M.R. Hamblin: Low-level laser therapy (LLLT) reduces oxidative stress in primary cortical neurons in vitro. J Biophotonics 2013, 6(10): 829-838. https://doi.org/10.1002/ibio.201200157

37. Amaroli, A., C. Pasquale, A. Zekiy, A. Utyuzh, S. Benedicenti, A. Signore, and S. Ravera: Photobiomodulation and Oxidative Stress: $980 \mathrm{~nm}$ Diode Laser Light Regulates Mitochondrial Activity and Reactive Oxygen Species Production. Oxid Med Cell Longev 2021, 2021: 1-11.

\section{https://doi.org/10.1155/2021/6626286}

38. Rezaeinezhad, A., P. Eslami, H. Mirmiranpour, and H. Ghomi: The effect of cold atmospheric plasma on diabetes-induced enzyme glycation, oxidative stress, and inflammation; in vitro and in vivo. Sci Rep 2019, 9(1): 1-11. https://doi.org/10.1038/s41598-019-56459-y

39. Rezaeinezhad, A., P. Eslami, G. Afrasiabpour, H. Mirmiranpour, and H. Ghomi: Effect of pulsed electric field on diabetes-induced glycated enzyme, oxidative stress, and inflammatory markers in vitro and in vivo. J Phys D Appl Phys 2021, 55(1): 015401.

https://doi.org/ 10.1088/1361-6463/ac2530

40. Mahmoud, M.F., N.A. Hassan, H.M. El Bassossy, and A. Fahmy: Quercetin protects against diabetes-induced exaggerated vasoconstriction in rats: effect on low grade inflammation. PLoS One 2013, 8(5): e63784.

\section{https://doi.org/10.1371/journal.pone.0063784}

41. Chen, S., H. Jiang, X. Wu, and J. Fang: Therapeutic effects of quercetin on inflammation, obesity, and type 2 diabetes. Mediat Inflamm 2016, 2016: 1-6.

https://doi.org/10.1155/2016/9340637

42. Aguirre, L., N. Arias, M. Teresa Macarulla, A. Gracia, and M. P Portillo: Beneficial effects of quercetin on obesity and diabetes. Open Nutraceuticals J 2011, 4(1): 189-198.

https://doi.org/ 10.2174/1876396001104010189

43. Refat, M.S., R.Z. Hamza, A.M.A. Adam, H.A. Saad, A.A. Gobouri, F.S. Al-Harbi, F.A. Al-Salmi, T. Altalhi, and S.M. ElMegharbel: Quercetin/Zinc complex and stem cells: A new drug therapy to ameliorate glycometabolic control and pulmonary dysfunction in diabetes mellitus: Structural characterization and genetic studies. PLoS One 2021, 16(3): e0246265. https://doi.org/10.1371/journal.pone.0246265

44. Xu, D., M.-J. Hu, Y.-Q. Wang, and Y.-L. Cui: Antioxidant activities of quercetin and its complexes for medicinal application. Molecules 2019, 24(6): 1123.

https://doi.org/10.3390/molecules24061123 
45. Ahmed, O.M., T. Mohamed, H. Moustafa, H. Hamdy, R.R. Ahmed, and E. Aboud: Quercetin and low level laser therapy promote wound healing process in diabetic rats via structural reorganization and modulatory effects on inflammation and oxidative stress. Biomed Pharmacother 2018, 101: 58-73.

https://doi.org/10.1016/j.biopha.2018.02.040

46. Bhuiyan, M.N.I., S. Mitsuhashi, K. Sigetomi, and M. Ubukata: Quercetin inhibits advanced glycation end product formation via chelating metal ions, trapping methylglyoxal, and trapping reactive oxygen species. Biosci Biotechnol Biochem 2017, 81(5): 882-890.

https://doi.org/10.1080/09168451.2017.1282805

47. Li, S., H. Cao, D. Shen, Q. Jia, C. Chen, and S.L. Xing: Quercetin protects against ox-LDL-induced injury via regulation of ABCAI, LXR- $\alpha$ and PCSK9 in RAW264. 7 macrophages. Mol Med Rep 2018, 18(1): 799-806.

https://doi.org/ 10.3892/mmr.2018.9048

48. Liang, Q., Y. Chen, C. Li, and L. Lu: Quercetin attenuates OxLDL-induced calcification in vascular smooth muscle cells by regulating ROS-TLR4 signaling pathway. South Med J 2018, 38(8): 980-985.

https://doi.org/ 10.3969/j.issn.1673-4254.2018.08.13

49. Zhao, B., Q. Zhang, X. Liang, J. Xie, and Q. Sun: Quercetin reduces inflammation in a rat model of diabetic peripheral neuropathy by regulating the TLR4/MyD88/NF-KB signalling pathway. Eur J Pharmacol 2021, 912(174607.

https://doi.org/10.1016/j.ejphar.2021.174607 